\title{
Microcomputers in Evaluation '83
}

Peter J. Gray

Northwest Regional Educational Laboratory

Microcomputer! The very word causes both fear and longing in the heart of the most seasoned evaluator. At Evaluation ' 83 nearly $10 \%$ of the sessions and the ENet President's Problem dealt explicitly with microcomputer technology and evaluation. These sessions attempted to dispel the fear and to focus the longing of evaluators.

Two general themes emerged from the sessions scattered throughout the conference. One was that microcomputers provide a powerful tool for the conduct of evaluation research. The other was that microcomputer use as a topic of evaluation study is an area of rapidly expanding interest.

\section{USING MICROCOMPUTERS IN EVALUATION}

At the start of the conference, Presession D instructors Peter Gray and Larry Picus provided participants with background information and hands-on experience with microcomputer-based word processing, data base management, spreadsheet and statistical analysis, instrument generation, and other applications. The purpose of this session was to demonstrate the utility of microcomputers from the beginning of the evaluation process (proposal writing and planning), to data collection and analysis, to the dissemination of results. The twelve-hour session ended with a discussion of the steps in planning for microcomputer use. Sara Steele echoed the emphasis on the uses of microcomputers in program evaluation in Evaluation Network (ENét) session 11. She discussed ten ways to increase the effectiveness of computers as tools for evaluation.

Several other conference presentations focused on particular uses of microcomputers. For example, participants in ENet session 5 reported using micros to make staffing projections and to develop presentation 
graphics ((Richard Murdach), to organize and analyze data (Nan Simpson), and to develop and evaluate adaptive testing procedures based on the Rasch model (Jenny Bosma). Also in ENet session 5, Michael Plog noted potential abuses of microcomputers in evaluation, such as when users expect them to do more than they are designed to do.

People-related abuses noted by Plog include turning research assistants into word processor operators, a fate akin to having key punching as one's main research experience. As part of ERS session 2, William Murphy described the establishment of a microcomputer data base management system for evaluation.

\section{EVALUATING MICROCOMPUTER USE}

Two of the presentations in ENet session 11 shifted the focus from using microcomputers in evaluation to evaluating their impact. Janice Mokos spoke about evaluating computer use in schools and, in particular, about asking the right questions. She noted that the first questions to ask concern the operation of the computer. It is only after descriptive information about the actual operation of the computer is obtained that more sophisticated questions about its impact can be addressed. Peter Senn gave a rousing presentation about the evaluation of microcomputer software. In his talk he pointed out the conflicts that arise in evaluating software and called for a better method than the myriad of checklists that currently abound. In ERS session 4, Charles McClintock discussed a study of microcomputer-based telecommunication.

\section{PLANNING FOR EVALUATION 84}

As the result of a symposium on professional uses of microcomputers (ENet session 20), led by Barbara Gross Davis and Peter Gray, a number of ways were identified in which next year's conference can help participants become better acquainted with (1) microcomputers as tools for doing evaluation, (2) microcomputer use as a topic of evaluation, and (3) microcomputers as vehicles for teaching about evaluation. Suggestions include providing demonstrations by vendors of software and 
hardware and presentations by fellow evaluators of the uses of microcomputers in doing evaluations.

The wide-ranging influence of this new technology might be illustrated by studies focusing on such topics as the evaluation of software (computer-assisted instructional software, statistical analysis software, and other application software); assessment of the equitable distribution, use, and impact of microcomputer technology; evaluation of computer curricula; and evaluation of such basic issues as the influence of microcomputers on student motivation. Such studies will of necessity concern policy analysis, cost analysis, decision theory, health-related issues, and legal and ethical questions.

Other suggestions for Evaluation ' 84 included swapping diskettes as part of the teaching materials exchange or as a separate activity; including specific microcomputer topics in the call for papers; and establishing columns in the publications of the Evaluation Network and Evaluation Research Society.

These columns would expand on the software notes that are currently published in Evaluation News. These columns would provide a forum for the spread of information about microcomputers, including calls for help on specific problems, updates of events sponsored by other organizations such as the American Educational Research Association (AERA) and Association for Educational Data Systems (AEDS), and announcements of events of interest such as the National Educational Computing Conference.

Based on the interest shown in the microcomputer-related sessions reported here and in the other new technology sessions, reported by Jere Johnston elsewhere, we can all look forward to a growing body of knowledge and experience in this area as the use and study of microcomputers spreads throughout the evaluation profession.

\title{
Conventional Methodology
}

\author{
Charles S. Reichardt \\ University of Denver
}

If there was a single theme that tied the methodological presentations at the recent ENet/ERS convention together, I didn't find it. However, it 